\title{
Application of the modified similarity-based method for cutting fluid selection
}

\author{
Kanika Prasad ${ }^{\mathrm{a}}$ and Shankar Chakraborty ${ }^{\mathbf{b}^{*}}$
}

${ }^{a}$ Department of Manufacturing Engineering, National Institute of Technology, Jamshedpur, India ${ }^{b}$ Department of Production Engineering, Jadavpur University, Kolkata, India

\section{H R O N I C L E}

Article history:

Received March 16, 2017

Received in revised format:

August 20, 2017

Accepted August 20, 2017

Available online

August 20, 2017

Keywords:

Cutting fluid selection

Multi-criteria decision making

Modified similarity-based method

Performance score

Ranking

\section{A B S T R A C T}

\begin{abstract}
An enormous amount of heat is released at the contact surface during machining of a component/partdue to friction, rubbing action and cutting forces generated. Cutting fluids are generally applied to provide lubrication and cooling at the tool and workpiece interface. They also play a beneficial role in machining operations, and enhance job shop's productivity, tool life and quality of the finished parts/products. In addition to these, they act as an important contributor in optimizing a machining operation. However, a cutting fluid suitable for a particular machining requirement may not be equally good for other applications and hence, there is a need for selection of the appropriate type of cutting fluid with a view to facilitate superlative and uncomplicated machining operation. Several factors, such as material ofthe cutting tool, operator's safety, compatibility with the machine tool, reliability and rancidity of the cutting fluid, and cost may all combine to limit the effectiveness or applicability of a cutting fluid. Therefore, the present study explores the potentiality of a modified similarity-based method, which is a multi-criteria decision making tool, in solving cutting fluid selection problems. To illustrate the procedural steps of this method, two real time problems are solved. The results obtained highly corroborate with the opinions of the experts in the related field, demonstrating the applicability of the said method.
\end{abstract}

(C) 2018 Growing Science Ltd. All rights reserved.

\section{Introduction}

In metal cutting industries, tribology plays a pivotal role. The existing challenges to tribology are oriented towards maintaining superior quality of productivity and increased utilization of the newly engineered materials. Since the fiscal and technological feasibility of a part/product is mainly governed by its surface finish and wear rate, knowledge regarding tribology can toughen the competition among the manufacturing organizations, and considerably bring down the energy and resources consumed by them. The contact temperature at the workpiece and cutting tool interface may sometimes reach above $1000^{\circ} \mathrm{C}$ while machining hard and difficult-to-cut materials. Because of which, chemical interactions, such as abrasion, adhesion, seizure and diffusion or complex combinations between the cutting tool, 
workpiece material, chips produced and environment are crucial during a machining operation (Comadury \& Larsen-Basse, 1989). Furthermore, the high cutting temperature generates residual stress, dimensional deformation, and a premature failure of the cutting tools (Nouioua et al., 2017). The severity of these chemical interactions in metal cutting can be greatly reduced through cooling and lubricationat the machining zone. Thus, a fluid's cooling and lubrication properties are critical in minimizing tool wear rate, and consequently improving tool life. They are also indispensible in attaining the desired shape, size and surface finish of the workpiece. Therefore, cutting fluids have wide applications in the manufacturing industries owing to their huge impact on the cutting tool's life, quality of the components/parts produced and efficiency of the machine tools utilized in the production process. Hence, it can be inferred that the use of these cutting fluids have traditionally resulted in a net reduction of manufacturers' operating costs (Hubbard et al., 2008).

Since the last two centuries, cutting fluids have been extensively utilized in metal cutting industries. At the beginning, simple oils were used to be applied with brushes to lubricate and cool down the machine tool, and seldom, lard, animal fat or whale oil was added to improve their lubricating ability. But, in response to dynamic and upsurging machining requirements, cutting fluids have evolved gradually from simple petroleum-based oils to complex blends of chemical additives, lubricants and water-based oils. Due to varying demands of the manufacturing organizations, several types of cutting fluid with different compositions are prevalent in the market to meet the explicit machining needs. In order to exploit the full potential of cutting fluid while in application, it is always recommended to select the most apposite cutting fluid for the specific machining requirement. The performance of a cutting fluid does not only depend upon its technological viability, but often also on several factors determined by the machine tool set-up, like chip removal, heat dissipation, lubrication of the machine parts and possibility of influencing chip breakage. The mode of application of cutting fluid can also range from flood to minimum quantity lubrication. However, the application method employed is usually governed by the requirements of machining application and availability of the equipment. It is observed that a machine operator usually utilizes his knowledge and experience while selecting a particular mode of application of cutting fluid. Hence, a scrupulous/conscientious choosing of cutting fluid for a specified machining requirement is critical while considering the following important aspects:

a) physical and chemical properties of the cutting fluid,

b) applicability of cutting fluids to various cutting tools and workpiece materials,

c) ability to perform different machining operations, and

d) economic considerations, such as purchasing cost, storage cost, operating cost, disposal cost, etc.

Several other factors, like compatibility with machine tool, operator interaction, performance requirements and environment friendliness also govern the selection of a cutting fluid (De Chiffre \& Belluco, 2002). One specific cutting fluid is highly suitable for a given machining condition, but may not be equally appropriate for another application. Moreover, several of the above-listed attributes may be both qualitative and quantitative in nature, sometimes having complex interrelationship (minimization of cost and maximization of safety, minimization of corrosion and maximization of cooling effect) among them. Such an in-depth analysis, however, is time consuming and requires clear understanding of the machining operation. Thus, selection of an apt cutting fluid is a baffling task. The complexity and difficulty associated with determining the most suitable cutting fluid from a list of feasible alternatives based on some evaluation criteria necessitate adopting a multi-criteria decision making (MCDM) tool, which can deal with such problems. Therefore, this paper explores the potentiality of an MCDM technique (Sandhya \& Garg, 2016; Sadatrasool et al., 2016; Anyaeche et al., 2017 ) in the form of a modified similarity-based method for solving cutting fluid selection problems. 


\section{Literature review}

In the past, tribology experts and researchers investigated the effects of application of different cutting fluids, and elucidated their importance during machining for different combinations of workpiece material, cutting tool material and material removal process. Axinte et al. (2001) examined the efficiency of six different cutting fluids in turning operation while comparing tool lives. Sales et al. (2001) enumerated an assortment of benefits and limitations of applying cutting fluids over dry machining operations. Soković and Mijanović (2001) studied the environmental parameters related to cutting fluids and their effect on machinability characteristics of workpiece materials. De Chiffre and Belluco (2002) presented a study on applicability of cutting fluids in various metal cutting operations. Cakir et al. (2007) studied about the application of cutting fluids for different combinations of machining operations, workpiece material and cutting tool material. Rao et al. (2007) analyzed the impact of emulsifier on the properties and performance of a cutting fluid. Jayal and Balaji (2009) studied the effect of different cutting fluid application methods on tool wear while machining AISI 1045 steel with carbide cutting tools.

Selection of a cutting fluid is often regarded as an MCDM problem where the variables have complex correlations among themselves, and many times, these relationships are subjective and abstract. The past researchers have developed and applied numerous MCDM methods for choosing appropriate cutting fluids for specific machining applications. Sutherland et al. (1997) developed an internet-based cutting fluid evaluation software test-bed (CFEST), which could provide quantitative information regarding performance, environmental impact, health and safety hazards, and cost for cutting fluid comparison and selection. Rao and Gandhi (2001) proposed a methodology based on digraph and matrix approachfor selection of the most apposite cutting fluid for a given machining application. Sun et al. (2001) evaluated the performance of grinding fluids while employing a two-grade fuzzy synthetic decision making system based on analytic hierarchy process (AHP). Tan et al. (2002) emphasized on green manufacturing and developed a multi-objective decision making model for cutting fluid selection. Rao and Patel (2010) employed preference ranking organization method for enrichment evaluations (PROMETHEE) for choosing cutting fluid while considering both crisp and fuzzy criteria values. Meciarova and Stanovsky (2011) developed a software for optimization of the cutting fluid selection procedure taking human safety and environmental hazards into consideration. Abhang and Hameedullah (2012) integrated technique for order preferenceby similarity to ideal solution (TOPSIS) and AHP method to select an apt lubricant from a number of available alternatives for machining of EN-31 steel workpiece with tungsten carbide inserts. Jagadish and Ray (2014 ${ }^{\mathrm{a}}$ ) combined AHP and Vlse Kriterijumska Optimizacija Kompromisno Resenje (VIKOR) methods to select the best cutting fluid for having reduced machining cost, while minimizing environmental impact and maximizing quality. Deshamukhya and Ray (2014) developed a decision support system based on AHP method for choosing the optimal cutting fluid to have minimum environmental impact. Jagadish and Ray (2014 $)$ employed multi-objective optimization on the basis of simple ratio analysis (MOOSRA) method for selecting the finest cutting fluid that would minimize the environmental impact and cost, and improve surface quality. Kumar and Prasad (2014) explained the procedural steps of Chi-square statistic and matrix approach for solving a cutting fluid selection problem for a given machining application. Chakraborty and Zavadskas (2014) employed an effective MCDM tool, i.e. weighted aggregated sum product assessment (WASPAS) method for cutting fluid selection. Tiwari and Sharma (2015) applied simple additive weighting (SAW) and weighted product (WPM) techniques for ranking different vegetable-based cutting fluid alternatives. Prasad and Chakraborty (2016) developed a quality function deployment (QFD)-based model for selecting cutting fluids according to some specific machining requirements.

It follows from the foregoing literature review that selecting an optimal cutting fluid is of great importance in manufacturing industries, and numerous methods have already been described to solve this decision making problem regarding cutting fluid selection. Moreover, similarity-based approach, 
an MCDM technique, has been successfully applied for ranking multi-criteria alternatives (Deng, 2007), ranking banks (Safariet al., 2013), personnel selection (Chaghooshi et al., 2014), ranking countries with respect to human development index (Safari \& Ebrahimi, 2014), evaluating economic companies (Moradi \& Ebrahimi, 2014), multi-objective optimization in drilling operation (Sonkar et al., 2014) etc. Therefore, for the first time, this paper evaluates the applicability and potentiality of a modified similarity-based approach in manufacturing sector for selection of cutting fluids in coherence with the machining requirements.

\section{Methodology}

Traditionally, the type of a cutting fluid for a particular machining application was often selected based on the recommendations of sales representatives of the cutting fluid suppliers devoid of clearly understanding the nature of machining operation and exact objectives of the cutting fluid application. However, selection of cutting fluids based on MCDM methods has gained attention in the last few decades. Therefore, in this paper, the potentiality of a new similarity method (modified similarity method), which is an extension of Deng's similarity measure concept (Deng, 2007), is investigated to facilitate decision making for the aforesaid MCDM problem. The performance scores of various cutting fluid alternatives that can perform the required machining operation, thus obtained through the abovementioned modified similarity method are compared to those of TOPSIS method. The study exhibits the application feasibility of the modified similarity method towards cutting fluid selection and related decision making in real time manufacturing environment.

This modified similarity-based methodis a customized form of TOPSIS methodology, which uses the concept of ideal solution for comparing two alternatives in such a way that the most preferred alternative should have the highest degree of similarity to the positive ideal solution (PIS) and lowest similarity to the negative ideal solution (NIS). Safari et al. (2013) emphasized on determining the conflicting index between two alternatives to show the degree of conflict between them. The concept of variable's gradient is employed here to calculate the conflicting index as it can explain conflicts between evaluation criteria in MCDM problems very well. If $A_{i}$ and $A_{j}$ represent two alternatives of a given MCDM problem, they can be considered as two vectors, and the angle between $A_{i}$ and $A_{j}$ in the $m$-dimensional real space measures the conflict between them. It can be interpreted from Fig. 1 that there is no conflict between $A_{i}$ and $A_{j}$ when $\theta_{i j}=0$, and the conflict occurs when $\theta_{i j} \neq 0$, i.e. $\theta_{i j} \in(0, \pi / 2)$ . When $\theta_{i j}=0$, the inclination of both the alternatives $A_{i}$ and $A_{j}$ is simultaneously increasing in the same direction and hence, there exists no conflict between them.

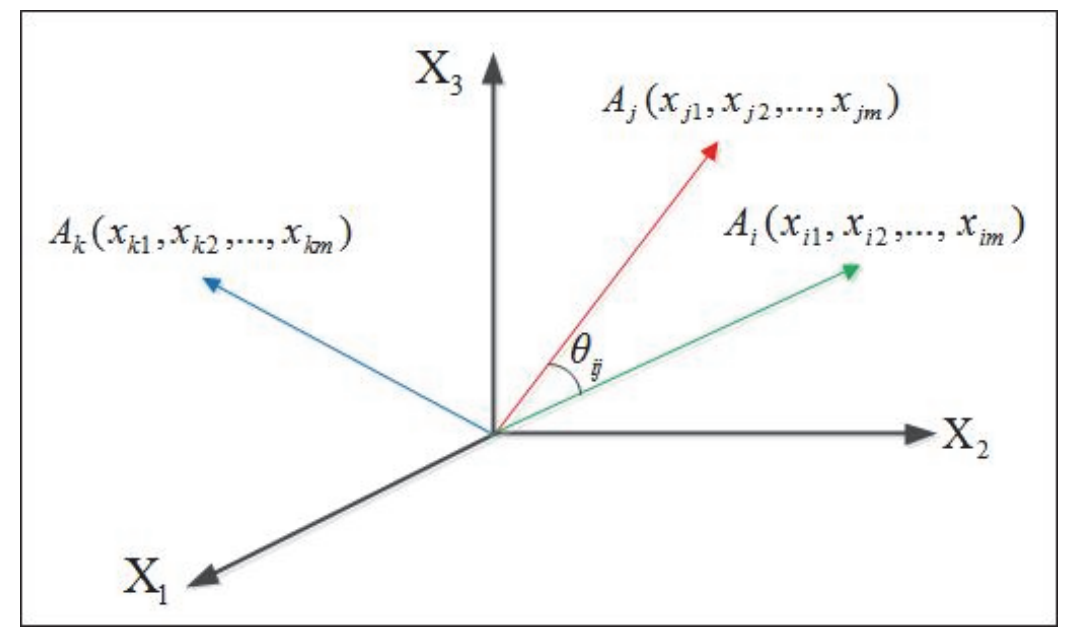

Fig. 1. Degree of conflict between alternatives by gradients

The degree of conflict between alternatives $A_{i}$ and $A_{j}$ is determined using the following equation: 


$$
\cos \theta_{i j}=\frac{\sum_{k=1}^{m} x_{i k} x_{j k}}{\left(\sum_{k=1}^{m} x_{i k}^{2}\right)^{0.5}\left(\sum_{k=1}^{m} x_{j k}^{2}\right)^{0.5}},
$$

where $\theta_{i j}$ is the angle between the gradients of alternatives, and $\left(x_{i 1}, x_{i 2}, \ldots, x_{i m}\right)$ and $\left(x_{j 1}, x_{j 2}, \ldots, x_{j m}\right)$ are the gradients of two alternatives $A_{i}$ and $A_{j}$ respectively.

The conflict index is represented by $\theta_{i j}=0$ and it shows that the corresponding gradient vectors lie in the same direction of improvement. In the same manner, the conflict index characterized by $\theta_{i j}=\pi / 2$ indicates that their gradient vectors have vertical relationship with each other. The procedural steps for solving MCDM problems while applying the modified similarity-based approach are presented as below:

Step 1: This step is characterized by establishing the decision matrix consisting of a set of alternatives $A_{i}(i=1,2, \ldots, n)$ to be evaluated against a set of criteria $C_{j}(j=1,2, \ldots, m)$.

$$
X=\left[\begin{array}{cccc}
x_{11} & x_{12} & \ldots & x_{1 m} \\
x_{21} & x_{22} & \ldots & x_{2 m} \\
: & : & : & : \\
x_{n 1} & x_{n 2} & \ldots & x_{n m}
\end{array}\right]
$$

Step 2: Determining the weighting vector is the next step. Let $w_{j}$ represents the relative importance of criterion $C_{j}$ with respect to the overall objective of the selection problem. Shannon's entropy method (Rao, 2007) is employed here for calculating priority weights of the considered criteria.

$$
W=\left(w_{1}, w_{2}, \ldots, w_{m}\right)
$$

Step 3: The ranking actually begins with normalizing the decision matrix through the Euclidean normalization technique to ensure that all the values in the matrix are dimensionless and can be compared with each other.

$$
x_{i j}^{\prime}=\frac{x_{i j}}{\left(\sum_{j=1}^{m} x_{i j}^{2}\right)^{0.5}}
$$

Thus, the normalized matrix can be obtained as follows:

$$
X^{\prime}=\left[\begin{array}{cccc}
x_{11}^{\prime} & x_{12}^{\prime} & \ldots & x_{1 m}^{\prime} \\
x_{21}^{\prime} & x_{22}^{\prime} & \ldots & x_{2 m}^{\prime} \\
\vdots & \vdots & : & \vdots \\
x_{n 1}^{\prime} & x_{n 2}^{\prime} & \ldots & x_{n m}^{\prime}
\end{array}\right]
$$

Step 4: In this step, the weighted performance matrix reflecting the performance of each alternative with respect to the evaluation criterion is obtained by multiplying the normalized decision matrix with the weight vector. This matrix is called the performance matrix.

$$
X_{w}^{\prime}=\left[\begin{array}{cccc}
w_{1} x_{11}^{\prime} & w_{2} x_{12}^{\prime} & \ldots & w_{3} x_{1 m}^{\prime} \\
w_{1} x_{21}^{\prime} & w_{2} x_{22}^{\prime} & \ldots & w_{3} x_{2 m}^{\prime} \\
: & : & : & : \\
w_{1} x_{n 1}^{\prime} & w_{2} x_{n 2}^{\prime} & \ldots & w_{3} x_{n m}^{\prime}
\end{array}\right]=\left[\begin{array}{cccc}
y_{11} & \mathrm{y}_{12} & \ldots & \mathrm{y}_{1 m} \\
y_{21} & y_{22} & \ldots & y_{2 m} \\
: & : & : & : \\
y_{n 1} & y_{n 2} & \ldots & y_{n m}
\end{array}\right]
$$


Step 5: Determining the PIS and NIS is based on the concept that they consist of the best (or worst) criteria values attainable from all the alternatives if each criterion takes monotonically increasing or decreasing values. This notion has been widely used in various multi-criteria analysis models for solving realtime decision making problems (Deng, 1999). The PIS and NIS can be obtained while employing the following equations:

$$
\left\{\begin{array}{l}
A_{j}^{+}=\max y_{i j} \\
A_{j}^{-}=\min y_{i j}
\end{array} \quad i=1,2, \ldots, n ; j=1,2, \ldots, m\right.
$$

Step 6: The next step comprises of calculating the degree of conflict between each alternative $A_{i}$ and the PIS $\left(A_{j}^{+}\right)$and NIS $\left(A_{j}^{-}\right)$in the $m$-dimensional real space. The angle between $A_{i}$ and $A_{j}^{+}\left(A_{j}^{-}\right)$in the $m$-dimensional real space, which is shown by $\theta_{i}^{+}\left(\theta_{i}^{-}\right)$is a good measure of conflict between the vectors. Fig. 2 shows the degree of conflict between the above-mentioned vectors. The degree of conflict between the alternatives is calculated using the following equations:

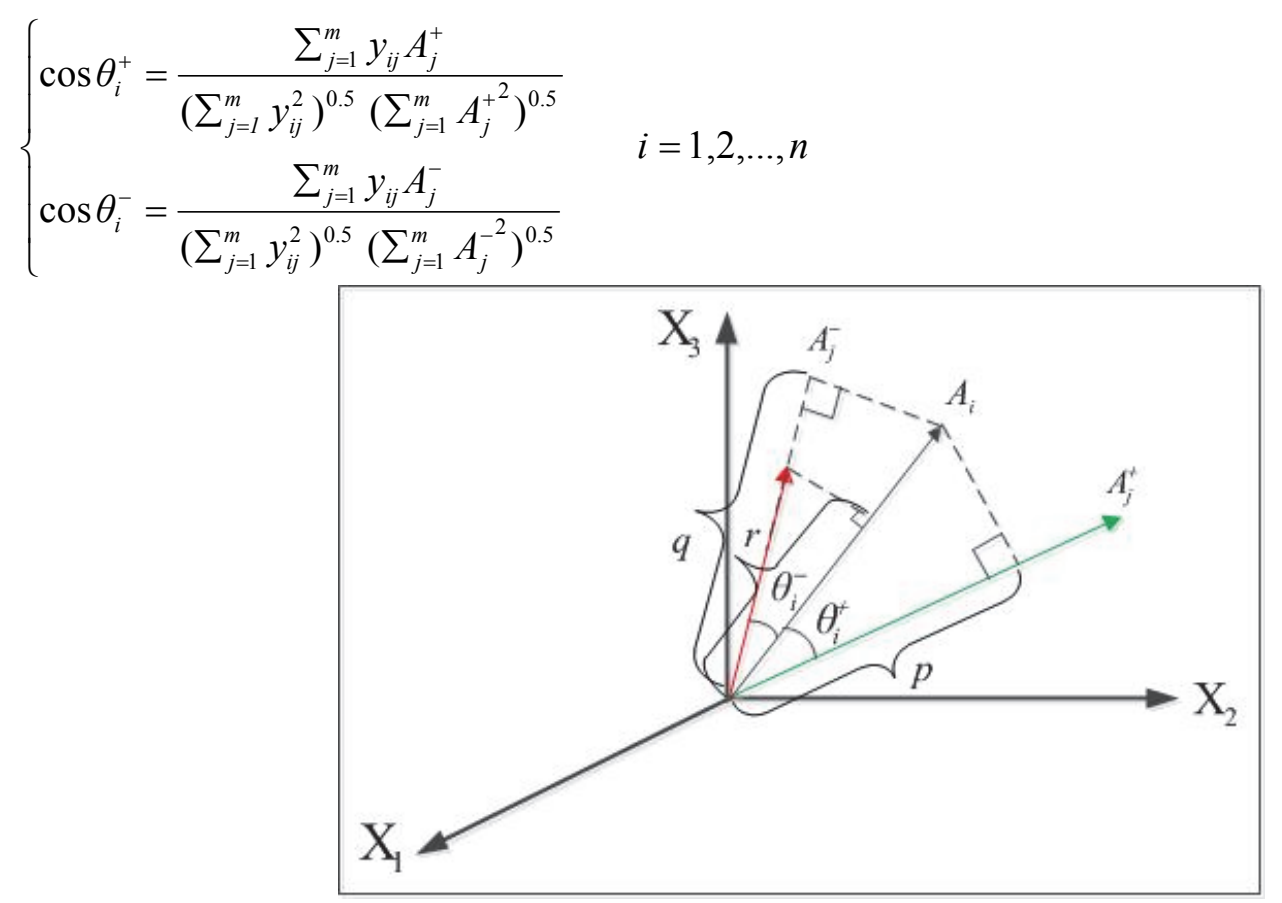

Fig. 2.Degree of conflict between alternatives and $A_{j}^{+}\left(A_{j}^{-}\right)$

Step 7: Once the degree of conflict is calculated, determining the degree of similarity between each pair of alternative, andthe PIS and NIS is the subsequent step. The degrees of similarity of the alternative $A_{i}$ to $A_{j}^{+}$and alternative $A_{i}$ to $A_{j}^{-}$are denoted through $S_{i}^{+}$and $S_{i}^{-}$respectively. Before computing the similarity index, the following point regarding Deng's similarity method needs to be discussed. It is evident from Fig. 2 that $p$ is the projection of alternative vector $A_{i}$ on the PIS vector $A_{j}^{+}$. Since the PIS has the largest value among the alternatives, the $A_{i}$ vector is equal or shorter than it. As a result, values for $S_{i}^{+}$range between 0 and 1. Similarly, $q$ is the projection of alternative vector $A_{i}$ on the NIS vector $A_{j}^{-}$. But in this case, as the NIS has the smallest valueamong the alternatives, $q$ is equal or longer than $A_{j}^{-}$, thus causing problem in Deng's method. In order to fix the problem, another vector is needed. As 
it is shown in Fig. 2, $r$ is the projection of the NIS vector $A_{j}^{-}$on the alternative vector $A_{i}$ which is always shorter than the alternative vector (Safari \& Ebrahimi, 2014). Therefore, the following equations are used to calculate the similarity index.

$$
\begin{aligned}
& S_{i}^{+}=\frac{\cos \theta_{i}^{+} \times\left(\sum_{j=1}^{m} y_{i j}^{2}\right)^{0.5}}{\left|A_{j}^{+}\right|} \\
& S_{i}^{-}=\frac{\left|A_{j}^{-}\right|}{\cos \theta_{i}^{-} \times\left(\sum_{j=1}^{m} y_{\mathrm{ij}}^{2}\right)^{0.5}}
\end{aligned}
$$

Step 8: Calculating the overall performance score for each alternative with respect to the considered criteria is the last step of this modified similarity-based method. The higher the performance index, the more preferred is the alternative.

$$
P_{i}=\frac{S_{i}^{+}}{S_{i}^{+}+S_{i}^{-}}
$$

In this method, since the angle between alternative $A_{i}$ and NIS (PIS) is not clear when it is equal to PIS (NIS), the value for the overall performance score is not equal to one (zero). Finally, the ranks for all the alternatives are obtained in decreasing order of their performance scores. A flowchart exhibiting the procedural steps for solving the cutting fluid selection problem while employing the modified similarity-based method is exhibited in Fig. 3.

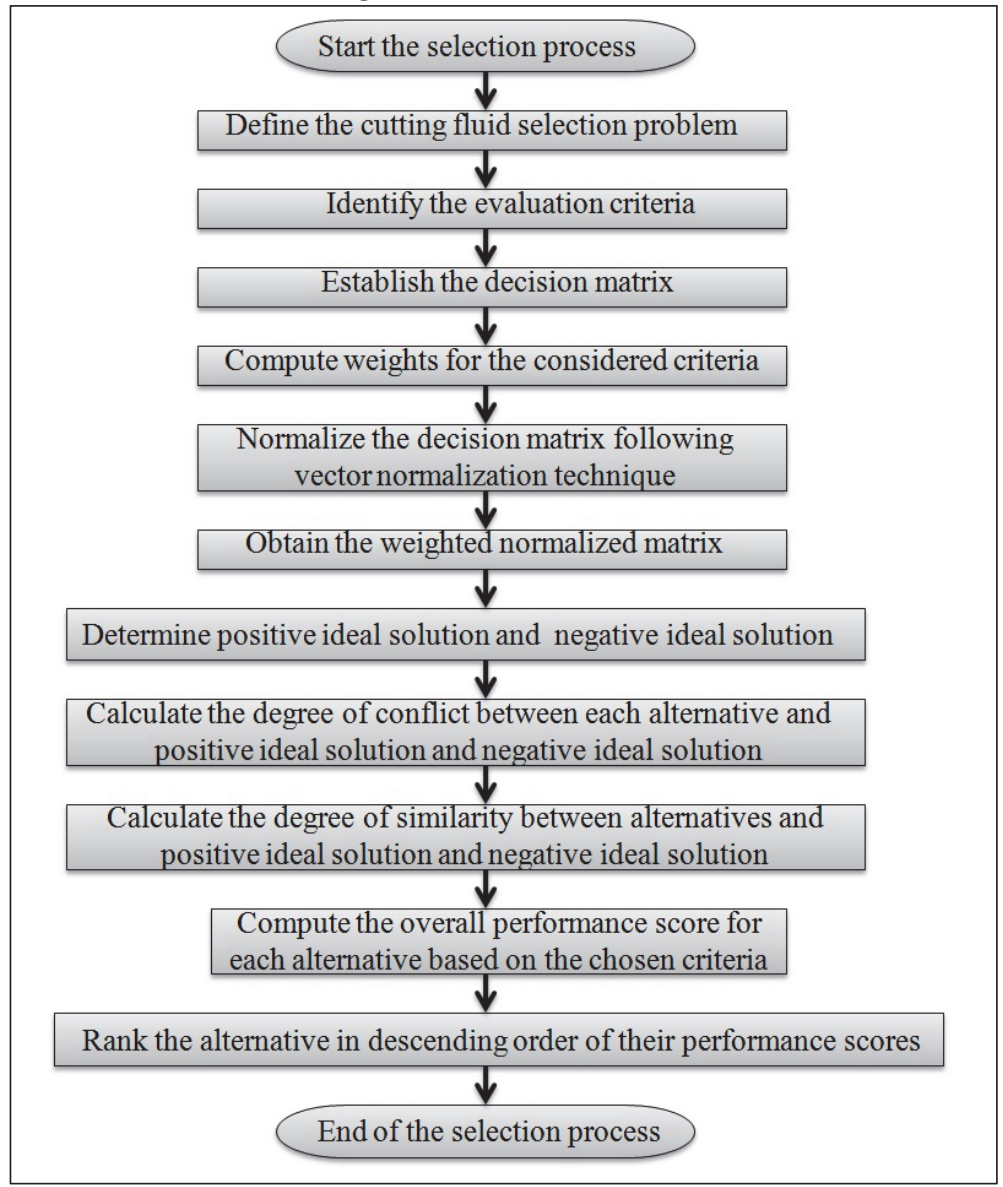

Fig. 3. Flowchart for the modified similarity-based method 


\section{Illustrative examples}

In order to reveal the computational accuracy and validate the applicability of the above-mentioned modified similarity-based approach for dealing with cutting fluid selection problems, the following two realtime examples are considered and consequently solved.

\subsection{Example 1}

In this example, a decision making problem regarding selection of the most suitable cutting fluid for cutting spur gears fabricated of alloy steel is considered. The tool material used for cutting gears is carbide. The machining process used for cutting gears is hobbing, which is usually a slow speed machining operation where the cut is quite heavyand continuous. The increase in temperature at the workpiece and tool interface adversely affects the dimensional accuracy and desired finish of the spur gears. In such severe applications, wetting agents (generally fatty esters) increase the cutting fluid's ability to coat the cutting tool, workpiece and metal fines, which thereby enhances its lubricating property and guards against microscopic welding. It has already been known that neat oils with extreme pressure additives (EPA), such as chlorine and sulphur, perform best in heavy duty machining operations on alloy steel. Cutting fluids with chlorine additive offers greater tool life at relatively low cutting speeds, while sulphur additives are used for machining of highalloy steels. Viscosity of a cutting fluid is also a vital property with respect to its performance and maintenance. Fluids with lower viscosity let micro-chip and dirt to settle out of the suspension. With increasing environmental regulation, trouble and cost associated with disposal of the cutting fluids have increased. On these days, minimizing the environmental footprint has also become a significant objective for both the manufacturers and end-users of cutting fluids. Therefore, in this example, seven neat oil alternatives are evaluated based on five properties of cutting fluid, i.e. viscosity at $40^{\circ} \mathrm{C}$ in cst, sulphur $\mathrm{wt} \%$, chlorine $\mathrm{wt} \%$, fatty ester $\mathrm{wt} \%$ and disposability in relative (R) scale which have significant effects on the given machining requirements. Disposability of cutting fluid is measured in $\mathrm{R}$ scale, while comparing its physical and chemical properties that affect the environment. The values 5 and 1 used for $\mathrm{R}$ scale symbolize the highest and the lowest disposability of the cutting fluid alternatives respectively. The higher value for disposability indicates that the effect of cutting fluid disposal in the environment is comparatively less harmful. The decision matrix comprising all the values related to the chosen criteria for different alternatives considered in this example is shown in Table 1. In addition, the last row of Table 1 contains the priority weights of all the criteria considered for evaluation which are computed using Shannon's entropy method to avoid any subjectivity in the decision making process. Next, following the steps of the modified similarity-based approach as elucidated in the previous section, selection of the most effective neat oil for cutting gears made of alloy steel among the identified candidate alternatives iscarried out. At first, the normalized values for the decision matrix employing the Euclidean normalization technique are attained within a scale of 0 to 1 , as displayed in Table 2.

Table 1. Decision matrix for neat oil selection problem

\begin{tabular}{cccccc}
\hline Alternative & \multicolumn{5}{c}{ Criteria } \\
\cline { 2 - 6 } & $\begin{array}{c}\text { Viscocity at } \\
40^{\circ} \mathrm{C}\left(\mathrm{C}_{1}\right)\end{array}$ & $\begin{array}{c}\text { Sulphur wt\% } \\
\left(\mathrm{C}_{2}\right)\end{array}$ & $\begin{array}{c}\text { Chlorine } w \mathrm{t} \% \\
\left(\mathrm{C}_{3}\right)\end{array}$ & $\begin{array}{c}\text { Fatty ester wt\% } \\
\left(\mathrm{C}_{4}\right)\end{array}$ & $\begin{array}{c}\text { Disposability } \\
\left(\mathrm{C}_{5}\right)\end{array}$ \\
\hline $\mathrm{A}_{1}$ & 12.5 & 2.8 & 1.8 & 0.5 & 4 \\
$\mathrm{~A}_{2}$ & 31.6 & 3.5 & 1 & 3 & 5 \\
$\mathrm{~A}_{3}$ & 13.5 & 2.3 & 1.1 & 5 & 5 \\
$\mathrm{~A}_{4}$ & 24.1 & 2.5 & 2.7 & 5 & 4 \\
$\mathrm{~A}_{5}$ & 45.1 & 2.4 & 2.6 & 5 & 3 \\
$\mathrm{~A}_{6}$ & 38.5 & 2.2 & 2.4 & 4 & 3 \\
$\mathrm{~A}_{7}$ & 21.6 & 1.1 & 3.5 & 7 & 4 \\
Weight & 0.0919 & 0.1621 & 0.2738 & 0.2748 & 0.1973 \\
\hline
\end{tabular}


Table 2

Normalized decision matrix for neat oil selection problem

\begin{tabular}{cccccc}
\hline & \multicolumn{5}{c}{ Criteria } \\
\cline { 2 - 6 } Alternative & $\mathrm{C}_{1}$ & $\mathrm{C}_{2}$ & $\mathrm{C}_{3}$ & $\mathrm{C}_{4}$ & $\mathrm{C}_{5}$ \\
\hline $\mathrm{A}_{1}$ & 0.1627 & 0.4248 & 0.2939 & 0.0409 & 0.3714 \\
$\mathrm{~A}_{2}$ & 0.4114 & 0.5310 & 0.1633 & 0.2456 & 0.4642 \\
$\mathrm{~A}_{3}$ & 0.1757 & 0.3490 & 0.1796 & 0.4093 & 0.4642 \\
$\mathrm{~A}_{4}$ & 0.3137 & 0.3793 & 0.4408 & 0.4093 & 0.3714 \\
$\mathrm{~A}_{5}$ & 0.5871 & 0.3641 & 0.4245 & 0.4093 & 0.2785 \\
$\mathrm{~A}_{6}$ & 0.5012 & 0.3338 & 0.3919 & 0.3274 & 0.2785 \\
$\mathrm{~A}_{7}$ & 0.2812 & 0.1669 & 0.5715 & 0.5730 & 0.3714 \\
\hline
\end{tabular}

In the next step, the degree of conflict between each alternative and PIS $\left(\cos \theta^{+}\right)$and NIS $\left(\cos \theta^{-}\right)$is computed from the performance matrix. The columns of the normalized decision matrix are multiplied by the associated criteria weights to obtain the corresponding performance matrix. The degree of similarity between the alternatives and PIS $\left(S^{+}\right)$and NIS $\left(S^{-}\right)$is then estimated. Finally, the overall performance score for each alternative is computed using Eq. (10) and all the values obtained are arranged in Table 3.

Table 3

Weighted normalized matrix for neat oil selection problem

\begin{tabular}{ccccccccccc}
\hline Alternative & $\mathrm{C}_{1}$ & $\mathrm{C}_{2}$ & $\mathrm{C}_{3}$ & $\mathrm{C}_{4}$ & $\mathrm{C}_{5}$ & $\cos \theta^{+}$ & $\cos \theta^{-}$ & $S^{+}$ & $S^{-}$ & $P_{i}$ \\
$\mathrm{~A}_{1}$ & 0.0150 & 0.0689 & 0.0805 & 0.0112 & 0.0733 & 0.8187 & 0.8541 & 0.4169 & 0.8434 & 0.3308 \\
$\mathrm{~A}_{2}$ & 0.0378 & 0.0861 & 0.0447 & 0.0675 & 0.0916 & 0.8624 & 0.8411 & 0.5205 & 0.7227 & 0.4186 \\
$\mathrm{~A}_{3}$ & 0.0162 & 0.0566 & 0.0492 & 0.1125 & 0.0916 & 0.9279 & 0.7086 & 0.5958 & 0.8064 & 0.4249 \\
$\mathrm{~A}_{4}$ & 0.0288 & 0.0615 & 0.1207 & 0.1125 & 0.0733 & 0.9948 & 0.7692 & 0.7509 & 0.6319 & 0.5430 \\
$\mathrm{~A}_{5}$ & 0.0540 & 0.0590 & 0.1162 & 0.1125 & 0.0550 & 0.9714 & 0.7912 & 0.7170 & 0.6282 & 0.5330 \\
$\mathrm{~A}_{6}$ & 0.0461 & 0.0541 & 0.1073 & 0.0900 & 0.0550 & 0.9723 & 0.8193 & 0.6330 & 0.6878 & 0.4793 \\
$\mathrm{~A}_{7}$ & 0.0258 & 0.0271 & 0.1565 & 0.1575 & 0.0733 & 0.9704 & 0.6722 & 0.8990 & 0.5891 & 0.6041 \\
\hline $\mathrm{A}(+)$ & 0.0150 & 0.0861 & 0.1565 & 0.1575 & 0.0916 & & & & & \\
$\mathrm{~A}(-)$ & 0.0540 & 0.0271 & 0.0447 & 0.0112 & 0.0550 & & & & & \\
\hline
\end{tabular}

When this selection problem is solved employing the modified similarity-based method, $\mathrm{A}_{7}$ emerges out as the most appropriate neat oil among all the considered alternatives for cutting gears based on the specified machining conditions. The alternatives $A_{4}$ and $A_{1}$ are identified as the second best and the least suitable choices respectively. The appropriateness of neat oil alternative $A_{7}$ can be justified while having a closer look at its various chemical properties. Here, viscosity is the sole non-beneficial criterion whose lower value is desired and the other four are beneficial attributes preferred with higher values. Although, $\mathrm{A}_{7}$ contains comparatively less sulphur wt $\%$, it has higher values for the other three beneficial criteria, i.e. chlorine wt $\%$, fatty ester $w t \%$ and disposability, and moderately lower value for viscosity. Hence, its selection with respect to the considered criteria can well be justified.

At the end, the results obtained are compared with those of TOPSIS methodology to validate the application of this method for selection of cutting fluids. The most and the least preferred choices of neat oil for cutting gears exactly match for the two said methods. A comparison between the outcomes of the two methodologies in the form of rankings of the alternatives in descending order of their performance scores is presented in Table 4. 
Table 4

Comparison between modified similarity and TOPSIS methods for neat oil selection problem

\begin{tabular}{ccccc}
\hline \multirow{2}{*}{ Alternative } & \multicolumn{2}{c}{ Modified similarity method } & \multicolumn{2}{c}{ TOPSIS method } \\
\cline { 2 - 5 } & $P_{i}$ & 7 & $P_{i}$ & Rank \\
\hline $\mathrm{A}_{1}$ & 0.3308 & 6 & 0.2954 & 7 \\
$\mathrm{~A}_{2}$ & 0.4186 & 5 & 0.3847 & 6 \\
$\mathrm{~A}_{3}$ & 0.4249 & 2 & 0.4956 & 5 \\
$\mathrm{~A}_{4}$ & 0.5430 & 3 & 0.6693 & 2 \\
$\mathrm{~A}_{5}$ & 0.5330 & 4 & 0.6007 & 3 \\
$\mathrm{~A}_{6}$ & 0.4793 & 1 & 0.5071 & 4 \\
$\mathrm{~A}_{7}$ & 0.6041 & & 0.7488 & 1 \\
\hline
\end{tabular}

\subsection{Example 2}

This example illustrates selection ofthecutting fluid for performing turning operation on copper-based materials employing high speed steel (HSS) tools. Few copper-based materials can be machined dry. However, dry cutting fails to produce required tool life and surface finish in some cases.Also, application of a cutting fluid is necessary to provide lubrication to various parts of the machine tool. Besides, it is a well known fact that HSS tools are capable of retaining their hardness only up to the temperature of around $550-600^{\circ} \mathrm{C}$. Thus, the cutting fluid must also possess cooling property while being machined with HSS tools. Moreover, cutting fluids containing sulphur may exhibit a propensity to react with copper and hence, a sulphur-free cutting fluid should be selected. Soluble oils with lower viscosity materialize as the ideal type of cutting fluid for the given machining conditions as they are simple to ply and remove from the cutting zone. Additionally, they must contain corrosion inhibitor and biocide which help in controlling the rancidity problems. Therefore, this cutting fluid selection problem evaluates nine soluble oil alternatives. Four properties of cutting fluid, like flash point in ${ }^{\circ} \mathrm{C}$, viscocity at $40^{\circ} \mathrm{C}$ in cst, density at $29^{\circ} \mathrm{C}$ in $\mathrm{g} / \mathrm{cm}^{3}$ and corrosion resistance in $\mathrm{R}$ scale are chosen as theimportant criteria for thisselection problem. The values 5 and 1 used in the $\mathrm{R}$ scale symbolize the highest and the lowest corrosion resistance of the cutting fluid alternatives respectively. Table 5 shows the decision matrix consisting of all the relevant data for the considered alternatives with respect to the evaluation criteriaselectedfor this problem. The priority weights for the four criteriaare also provided in this table. Table 6 exhibits the normalized decision matrix.

Table 5

Decision matrix for soluble oil selection problem

\begin{tabular}{ccccc}
\hline $\begin{array}{c}\text { Criteria } \\
\text { Alternative }\end{array}$ & $\begin{array}{c}\text { Flash point } \\
\left(\mathrm{C}_{1}\right)\end{array}$ & $\begin{array}{c}\text { Corrosion resistance } \\
\left(\mathrm{C}_{2}\right)\end{array}$ & $\begin{array}{c}\text { Viscocity at } 40^{\circ} \mathrm{C} \\
\left(\mathrm{C}_{3}\right)\end{array}$ & $\begin{array}{c}\text { Density at } 29^{\circ} \mathrm{C} \\
\left(\mathrm{C}_{4}\right)\end{array}$ \\
\hline $\mathrm{A}_{1}$ & 182 & 4 & 15 & 0.859 \\
$\mathrm{~A}_{2}$ & 200 & 3 & 23 & 0.862 \\
$\mathrm{~A}_{3}$ & 210 & 5 & 32 & 0.874 \\
$\mathrm{~A}_{4}$ & 220 & 5 & 46 & 0.877 \\
$\mathrm{~A}_{5}$ & 210 & 5 & 33 & 0.818 \\
$\mathrm{~A}_{6}$ & 215 & 5 & 42 & 0.864 \\
$\mathrm{~A}_{7}$ & 200 & 5 & 24 & 0.853 \\
$\mathrm{~A}_{8}$ & 205 & 3 & 27 & 0.867 \\
$\mathrm{~A}_{9}$ & 200 & 4 & 10 & 0.887 \\
Weight & 0.1408 & 0.3315 & 0.2533 & 0.2744 \\
\hline
\end{tabular}


Table 6

Normalized decision matrix for soluble oil selection problem

\begin{tabular}{ccccc}
\hline Alternative & $\mathrm{C}_{1}$ & $\mathrm{C}_{2}$ & $\mathrm{C}_{3}$ & $\mathrm{C}_{4}$ \\
\hline $\mathrm{A}_{1}$ & 0.2974 & 0.2894 & 0.1661 & 0.3320 \\
$\mathrm{~A}_{2}$ & 0.3268 & 0.2171 & 0.2547 & 0.3331 \\
$\mathrm{~A}_{3}$ & 0.3431 & 0.3618 & 0.3544 & 0.3378 \\
$\mathrm{~A}_{4}$ & 0.3595 & 0.3618 & 0.5095 & 0.3389 \\
$\mathrm{~A}_{5}$ & 0.3431 & 0.3618 & 0.3655 & 0.3161 \\
$\mathrm{~A}_{6}$ & 0.3513 & 0.3618 & 0.4652 & 0.3339 \\
$\mathrm{~A}_{7}$ & 0.3268 & 0.3618 & 0.2658 & 0.3297 \\
$\mathrm{~A}_{8}$ & 0.3350 & 0.2171 & 0.2990 & 0.3351 \\
$\mathrm{~A}_{9}$ & 0.3268 & 0.2894 & 0.1108 & 0.3428 \\
\hline
\end{tabular}

With respect to the performance scores of nine alternativesas given in Table 7,their ranking order is obtained as $\mathrm{A}_{4}-\mathrm{A}_{6}-\mathrm{A}_{3}-\mathrm{A}_{5}-\mathrm{A}_{7}-\mathrm{A}_{8}-\mathrm{A}_{1}-\mathrm{A}_{2}-\mathrm{A}_{9}$.

Table 7

Weighted normalized matrix for soluble oil selection problem

\begin{tabular}{cccccccccc}
\hline Alternative & $\mathrm{C}_{1}$ & $\mathrm{C}_{2}$ & $\mathrm{C}_{3}$ & $\mathrm{C}_{4}$ & $\cos \theta^{+}$ & $\cos \theta^{-}$ & $S^{+}$ & $S^{-}$ & $P_{i}$ \\
\hline $\mathrm{A}_{1}$ & 0.0419 & 0.0959 & 0.0421 & 0.0911 & 0.9919 & 0.8676 & 0.8879 & 1.4315 & 0.3858 \\
$\mathrm{~A}_{2}$ & 0.0460 & 0.0720 & 0.0645 & 0.0914 & 0.9474 & 0.9479 & 0.8233 & 1.3497 & 0.3778 \\
$\mathrm{~A}_{3}$ & 0.0483 & 0.1199 & 0.0898 & 0.0927 & 0.9681 & 0.9410 & 1.0917 & 1.0477 & 0.5086 \\
$\mathrm{~A}_{4}$ & 0.0506 & 0.1199 & 0.1291 & 0.0930 & 0.9143 & 0.9766 & 1.1602 & 0.8971 & 0.5582 \\
$\mathrm{~A}_{5}$ & 0.0483 & 0.1199 & 0.0926 & 0.0867 & 0.9627 & 0.9429 & 1.0765 & 1.0544 & 0.5030 \\
$\mathrm{~A}_{6}$ & 0.0495 & 0.1199 & 0.1178 & 0.0916 & 0.9300 & 0.9694 & 1.1354 & 0.9394 & 0.5426 \\
$\mathrm{~A}_{7}$ & 0.0460 & 0.1199 & 0.0673 & 0.0905 & 0.9893 & 0.9016 & 1.0439 & 1.1686 & 0.4726 \\
$\mathrm{~A}_{8}$ & 0.0472 & 0.0720 & 0.0757 & 0.0919 & 0.9318 & 0.9665 & 0.8453 & 1.2681 & 0.3974 \\
$\mathrm{~A}_{9}$ & 0.0460 & 0.0959 & 0.0281 & 0.0941 & 0.9883 & 0.8169 & 0.8832 & 1.5228 & 0.3720 \\
\hline $\mathrm{A}(+)$ & 0.0506 & 0.1199 & 0.0421 & 0.0867 & & & & & \\
$\mathrm{~A}(-)$ & 0.0419 & 0.0720 & 0.1291 & 0.0941 & & & & & \\
\hline
\end{tabular}

The modified similarity index method identifies alternative $\mathrm{A}_{4}$ as the most suitable soluble oil for performing turning operation on copper-based materials using HSS tools. It is followed by alternative $\mathrm{A}_{6}$, and alternative $\mathrm{A}_{9}$ emerges out as the least preferred soluble oil based on the specified machining requirements. Finally, the ranking obtained using the modified similarity index method is compared with that derived employing TOPSIS methodology, as shown in Table 8. From this table, it can be inferred that the first,second andlast choices of the cutting fluid for performing turning operation on copper-based materials are the same for both these methods.

Table 8

Comparison between modified similarity and TOPSIS methods for soluble oil selection problem

\begin{tabular}{ccccc} 
Alternative & \multicolumn{2}{c}{ Modified similarity method } & \multicolumn{2}{c}{ TOPSIS method } \\
\cline { 2 - 5 } & $P_{i}$ & 7 & $P_{i}$ & Rank \\
\hline $\mathrm{A}_{1}$ & 0.3858 & 8 & 0.2508 & 8 \\
$\mathrm{~A}_{2}$ & 0.3778 & 3 & 0.4906 & 6 \\
$\mathrm{~A}_{3}$ & 0.5086 & 1 & 0.4922 & 5 \\
$\mathrm{~A}_{4}$ & 0.5582 & 4 & 0.6654 & 1 \\
$\mathrm{~A}_{5}$ & 0.5030 & 2 & 0.5072 & 4 \\
$\mathrm{~A}_{6}$ & 0.5426 & 5 & 0.6337 & 2 \\
$\mathrm{~A}_{7}$ & 0.4726 & 6 & 0.3326 & 7 \\
$\mathrm{~A}_{8}$ & 0.3974 & 9 & 0.5644 & 3 \\
$\mathrm{~A}_{9}$ & 0.3720 & & 0.2029 & 9 \\
\hline
\end{tabular}




\section{Conclusions}

Selection of cutting fluid is typically an MCDM problem where the optimal course of decision needs to be taken in presence of multiple, usually conflicting criteria. In this paper, a modified similarity index method is employed for solving such problems. The essence of this method lies in the fact that it is based on the concept of alternative gradient and magnitude which are effective in addressing the concern of TOPSIS method that the applicability of an alternative cannot only be determined by the distance between the alternatives. Here, the concept of degree of similarity between the alternatives and the ideal solution is integrated together to obtain the overall performance score of each cutting fluid alternative considered for a particular machining requirement. This method is based on a rational and logical approach for solving MCDM problems, as it considers a scalar value accountable for both the best and the worst alternatives at the same time. The main advantage associated with this method is its simple computational steps that can be easily programmed in spreadsheets and hence, saving a lot of time. Moreover, the results obtained by this method are in accordance with the experts of the relevant domain. As a result, it can be concluded that this method possesses a huge potentiality in solving real time MCDM problems prevalent in the manufacturing environment very effectively. A study related to sensitivity analysis and effect of various normalization techniques on the adopted method may include the future scope of this work.

\section{Acknowledgement}

The authors would like to thank the anonymous referees for constructive comments on earlier version of this paper.

\section{References}

Abhang, L.B., \& Hameedullah, M. (2012). Selection of lubricant using combined multiple attribute decision making method. Advances in Production Engineering and Management,7(1), 39-50.

Anyaeche, C., Ighravwe, D., \& Asokeji, T. (2017). Project portfolio selection of banking services using COPRAS and Fuzzy-TOPSIS. Journal of Project Management, 2(2), 51-62.

Axinte, D.A., Belluco, W., \& De Chiffre, L. (2001). Reliable tool life measurements in turning - An application to cutting fluid efficiency evaluation. International Journal of Machine Tools and Manufacture,41(7), 1003-1014.

Cakir, O., Yardimeden, A., Ozben, T., \& Kilickap, E. (2007). Selection of cutting fluids in machining processes. Journal of Achievements in Materials and Manufacturing Engineering,25(2), 99-102.

Chaghooshi, A.J., Janatifar, H., \& Dehghan, M.(2014). An application of ahp and similarity-based approach to personnel selection. International Journal of Business Management and Economics, $1(1), 24-32$.

Chakraborty, S., \& Zavadskas, E.K. (2014). Applications of WASPAS method in manufacturing decision making. Informatica,25(1), 1-20.

Comadury, R., \& Larsen-Basse, J. (1989). Tribology: The cutting edge. Mechanical Engineering.

De Chiffre, L., \& Belluco, W. (2002). Investigations of cutting fluid performance using different machining operations. Lubrication Engineering,58, 22-29.

Deng, H.(1999). Multicriteria analysis with fuzzy pairwise comparison. International Journal of Approximate Reasoning, 21(3), 215-231.

Deng, H.(2007). A similarity-based approach to ranking multicriteria alternatives. International Conference on Intelligent Computing, Lecture Notes in Artificial Intelligence,4682, 253-262.

Deshamukhya, T., \& Ray, A. (2014). Selection of cutting fluid for green manufacturing using analytical hierarchy process (AHP): A case study. International Journal of Mechanical Engineering and Robotics Research,3(1), 173-182. 
Hubbard, K. M., Callahan, R.N., \&Strong. S.D. (2008). A standardized model for the evaluation of machining coolant/lubricant costs. International Journal of Advanced Manufacturing Technology,36(1), 1-10.

Jagadish, \& Ray, A. $\left(2014^{\text {a }}\right)$. Cutting fluid selection for sustainable design for manufacturing: An integrated theory. Procedia Materials Science, 6, 450-459.

Jagadish,\& Ray, A. $\left(2014^{\mathrm{b}}\right)$. Green cutting fluid selection using MOOSRA method. International Journal of Research in Engineering and Technology,3(3), 559-563.

Jayal, A.D., \& Balaji, A.K. (2009). Effects of cutting fluid application on tool wear in machining: Interactions with tool-coatings and tool surface features. Wear,267(9-10),1723-1730.

Kumar, E. S. R. R., \& Prasad, J. S. R. (2014). A novel approach of obtaining theoretical values in selection of cutting fluid attributes. IOSR Journal of Mathematics, 10(5), 1-4.

Meciarova, J., \& Stanovsky, M. (2011). Cutting fluids evaluation based on occupational health and environmental hazards. Engineering for Rural Development, 10, 418-422.

Moradi, M., \& Ebrahimi, E. (2014). Applying fuzzy AHP and similarity-based approach for economic evaluating companies based on corporate governance measures. Global Journal of Management Studies and Researches, 1(1), 10-20.

Nouioua, M., Yallese, M.A., Khettabi, R., Belhadi, S., \& Mabrouki, T. (2017). Comparative assessment of cooling conditions, including MQL technology on machining factors in an environmentally friendly approach. International Journal of Advanced Manufacturing Technology, DOI: 10.1007/s00170-016-9958-5.

Prasad, K., \& Chakraborty, S. (2016). Aquality function deployment-based model forcutting fluid selection. Advances in Tribology, http://dx.doi.org/10.1155/2016/3978102.

Rao, N.D., Srikant, R.R., \& Rao, C.S. (2007). Influence of emulsifier content on properties and durability of cutting fluids. Journal of the Brazilian Society of Mechanical Science and Engineering,24(4), 396-400.

Rao, R.V., \& Gandhi, O.P. (2001). Digraph and matrix method for selection, identification and comparison of metal cutting fluids. Journal of Engineering Tribology,215(1), 25-33.

Rao,R.V.(2007). Decision making in the manufacturing environment using graph theory and fuzzy multiple attribute decision making methods. Springer-Verlag, London.

Rao, R.V., \& Patel, B.K. (2010). Decision making in the manufacturing environment using an improved PROMETHEE method. International Journal of Production Research,48(16), 4665-4682.

Safari, H., Khanmohammadi, E., Hafezamini, A., \& Ahangari, S.S. (2013). A new technique for multi criteria decision making based on modified similarity method. Middle-East Journal of Scientific Research,14(5), 712-719.

Safari, H., \& Ebrahimi, E.(2014). Using modified similarity multiple criteria decision making technique to rank countries in terms of human development index. Journal of Industrial Engineering and Management, 7(1), 254-275.

Sales, W.F., Diniz, A.E., Machado, A.R. (2001). Application of cutting fluids in machining processes. Journal of the Brazilian Society of Mechanical Sciences,23(2), 227-240.

Sadatrasool, M., Bozorgi-Amiri, A., \& Yousefi-Babadi, A. (2016). Project manager selection based on project manager competency model: PCA-MCDM Ap-proach. Journal of Project Management, 1(1), 7-20.

Sandhya, S., \& Garg, R. (2016). Implementation of multi-criteria decision making approach for the team leader selection in IT sector. Journal of Project Management, 1(2), 67-75.

Soković, M., \& Mijanović, K. (2001). Ecological aspects of the cutting fluids and its influence on quantifiable parameters of the cutting processes.Journal of Materials Processing Technology,109(12), 181-189.

Sonkar, V., Abhishek, K., Datta, S., \& Mahapatra, S. S. (2014). Multi-objective optimization in drilling of GFRP composites : A degree of similarity approach. Procedia Materials Science, 6, 538-543.

Sun, J., Ge, P., \&Liu, Z. (2001). Two-grade fuzzy synthetic decision-making system with use of an analytic hierarchy process for performance evaluation of grinding fluids. Tribology International,34(10), 683-688. 
Sutherland, J.W., Cao, T., Daneil, C.M., Yue, Y., Zheng, Y., Sheng, P., Bauer, D., Srinivasan, M., DeVor, R.E., Kapoor, S.G., \& Skerlos, S.J. (1997). CFEST: An internet-based cutting fluid evaluation software testbed. North American Manufacturing Research Institution of the Society of Manufacturing Engineers, 25, 243-248.

Tan, X.C.,Lin, F., Cao, H.J., \& Zang, H. (2002). A decision-making framework model of cutting fluid selection for green manufacturing and a case study. Journal of Materials Processing Technology, 129(1-3), 467-470.

Tiwari, V.V., \& Sharma, A.(2015). MADM for selection of vegetable based cutting fluids by SAW method and WPM method. International Journal of Research in Technology and

Management,1(1), 16-27.

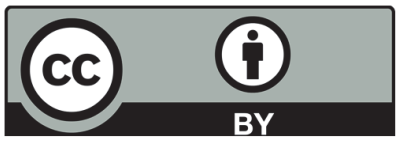

(C) 2018 by the authors; licensee Growing Science, Canada. This is an open access article distributed under the terms and conditions of the Creative Commons Attribution (CC-BY) license (http://creativecommons.org/licenses/by/4.0/). 